\title{
Decreased number of days of fever detection and duration of fever with continuous intake of a fermented milk drink: a randomized, double-blind, placebo- controlled study of elderly nursing home residents
}

\author{
Akira KUSHIRO ${ }^{1}$, Kensuke SHIMIZU1 ${ }^{1}$, Toshihiko TAKADA ${ }^{1}$, Itsumi KUSUNOKI ${ }^{2}$ and Naomi AIBA ${ }^{2}$ \\ ${ }^{1}$ Yakult Central Institute, 5-11 Izumi, Kunitachi, Tokyo 186-8650, Japan \\ ${ }^{2}$ Department of Nutrition and Life Science, Kanagawa Institute of Technology, 1030 Shimoogino, Atsugi, Kanagawa 243-0292, Japan
}

Received February 28, 2019; Accepted August 10, 2019; Published online in J-STAGE September 6, 2019

We conducted a randomized, double-blind, placebo-controlled parallel study to investigate the effects of a fermented milk on elderly nursing home residents. Eighty-eight participants each drank one bottle of fermented milk containing Lactobacillus casei strain Shirota, or a placebo, on a daily basis for 6 months in winter. Peripheral blood, saliva, fecal samples, and clinical data were analyzed to assess the milk's efficacy. Fermented milk consumption was associated with a significant decrease in the number of days on which fever was detected and the mean duration of fever compared with these values in the placebo group. No significant differences were observed in other biological parameters. Continuous intake of this fermented milk could be beneficial for the elderly in terms of suppressing the number of days of detection of fever and the duration of fever, which usually increase in winter.

Key words: probiotics, elderly, fever, fermented milk drink

\section{INTRODUCTION}

The elderly are susceptible to infection, and infections in residents in an aged-care facility easily spread to other residents and staff. As the immune response becomes compromised with age, infections can become refractory and symptom severe [1]. Pyrexia is an indicator of infectious disease, and regular observation for fever results in prompt medical care. It is important in the elderly to decrease the incidence and duration of fever because persistent fever leads to dehydration and more serious complications $[2,3]$.

There have been several reports of the ability of a fermented milk containing Lactobacillus casei strain Shirota (LcS) to prevent infectious disease [4-7] and modulate immune function (e.g., natural killer cell activity) [8,9]. Consumption of fermented milk also has beneficial effects on bowel movements and helps alleviate the symptoms of constipation, which can be a problem in the elderly [10].

Here, we examined the efficacy of fermented milk consumption in suppressing fever, alleviating constipation, improving peripheral blood and salivary secretory $\operatorname{IgA}(\mathrm{s} \operatorname{IgA})$ parameters, and modulating fecal microbiota.

\footnotetext{
*Corresponding author. Naomi Aiba (E-mail: aiba@bio.kanagawait.ac.jp)

(C)2019 BMFH Press

This is an open-access article distributed under the terms of the Creative Commons Attribution Non-Commercial No Derivatives (by-nc-nd) License. (CC-BY-NC-ND 4.0: https://creativecommons.org/licenses/by-nc-nd/4.0/)
}

\section{MATERIALS AND METHODS}

Subjects

The study subjects were residents of the Morinoie Katori nursing home (MK; Chiba, Japan) or the Morinoie Yashio nursing home (MY; Saitama, Japan). The inclusion criteria were as follows: elderly person (over 60 years old) living in MK or MY, able to take a test drink for 6 months, and able to give written informed consent either directly or through their family. The exclusion criteria were inability to ingest the test drink, deterioration of health status during the study inclusion period, milk allergy or lactose intolerance, habitual intake of fermented milk products or inability to discontinue taking them during the test period, or judgment by the principal medical doctor of the respective nursing home as inappropriate for trial participation. The trial was approved by the Ethics Committee of Kanagawa Institute of Technology (Kanagawa, Japan) and performed in compliance with the principles of the Helsinki Declaration. Details of the trial (including purpose, risks, and human rights protection) were explained to subjects or their families, and written informed consent was obtained from 88 subjects or their families before inclusion in the trial.

\section{Test drinks}

The test drinks were a fermented milk product and a placebo. Each $65-\mathrm{ml}$ bottle of the fermented milk drink contained at least $1.5 \times 10^{10} \mathrm{cfu}$ of Lactobacillus casei strain Shirota (LcS; our collection strain number is YIT 9029), sugar, skimmed milk, high-fructose corn syrup, and flavor. 
The nutrient composition of one bottle was $50 \mathrm{kcal}$ of energy, $0.8 \mathrm{~g}$ of protein, $0.1 \mathrm{~g}$ of lipid, $11.5 \mathrm{~g}$ of carbohydrate, and $12 \mathrm{mg}$ of sodium. The placebo drink contained the same components as the fermented milk drink but did not contain any bacteria. The taste of the placebo drink was made similar to that of the fermented milk drink by adding lactic acid. The taste, flavor, and external appearance of the placebo were indistinguishable from those of the fermented milk drink. The fermented milk drink and the placebo drink were both manufactured and distributed by Yakult Honsha Co., Ltd (Tokyo, Japan). They were refrigerated until ingestion.

\section{Study design}

The study was a randomized, double-blind, placebocontrolled parallel group trial. The participants lived in blocks in each facility; each block contained 5 to 14 residents. Residents of each block gathered in the block's dining room to eat. Because the subjects were instructed to have the test drink during breakfast, each block was allocated to a fermented milk-drink ingestion group (LcS group) or a placebo drink ingestion group (placebo group). Allocation lists were compiled by a person who was not in charge of sample or data analysis and were not been revealed until all the data had been processed. Nursing care level [11], age, and gender did not differ significantly between the two groups.

During the 6-month ingestion period, subjects consumed one bottle of the test drink on a daily basis. Before and at the end of the ingestion period, peripheral blood, saliva, and fecal samples were taken. For operational reasons, the ingestion period started in October 2013 and ended in March 2014 at MK, whereas it started in November 2013 and ended in April 2014 at MY. Clinical data on fever, bowel movements, diarrhea, and suppository and enema use were gathered from each subject's nursing care diary. Pyrexia was considered to be present when the body temperature was $37^{\circ} \mathrm{C}$ or more. Basically body temperature was measured once a day; however, in the event of pyrexia, body temperature was measured several times a day. The duration of fever was counted from the day when the body temperature was $37^{\circ} \mathrm{C}$ or more to the day when the body temperature decreased to less than $37^{\circ} \mathrm{C}$. Baseline data for the pre-ingestion period were obtained from patient diaries for the 6-month period before the ingestion period (from April 2013 to September 2013 at MK and from May 2013 to October 2013 at MY).

\section{Peripheral blood analysis}

Ten milliliters of peripheral blood was taken before and at the end of the ingestion period. Serum concentrations of iron, copper, zinc, and albumin were measured by LSI Medience Corporation (Hino, Japan). Transformation testing of lymphocytes stimulated by phytohemagglutinin (PHA) was also done by LSI Medience Corporation. The stimulation index (SI) in the lymphocyte transformation test was calculated by dividing the amount of incorporated ${ }^{3} \mathrm{H}$-thymidine (count per minute, cpm) upon PHA stimulation by the amount of incorporated ${ }^{3} \mathrm{H}$-thymidine (cpm) without stimulation. We were unable to collect enough blood from some participants to measure all of the analytical items. In these cases, some items were not analyzed.

\section{Fecal sample analysis}

Fecal samples were collected before and at the end of the ingestion period. About $1 \mathrm{~g}$ of fecal sample was taken by facility staff and suspended in RNAlater solution (Thermo Fisher Scientific Inc., Waltham, MA, USA) for microbiota analysis. Another approximately $1 \mathrm{~g}$ of fecal sample was placed into an empty tube for the measurement of fecal organic acid concentration. Fecal samples were transported to Yakult Central Institute (Tokyo, Japan), where RNA was extracted and counts for Bifidobacterium, Clostridium perfringens, and Enterobacteriaceae were determined by reverse transcriptionquantitative PCR $[5,12]$. The sequences of PCR primers and PCR conditions were described previously [12]. Organic acid was extracted from fecal samples and analyzed by HPLC [13]. Total organic acid was the sum of lactic acid, formic acid, acetic acid, propionic acid, butyric acid, iso-butyric acid, succinic acid, valeric acid, and iso-valeric acid. Fecal sample analysis was done by Yakult Central Institute. We were unable to analyze fecal samples for some participants because they did not allow facility staff to collect fecal samples.

\section{Salivary sIgA analysis}

Saliva samples were collected before and at the end of the ingestion period by facility staff and transported to and analyzed by LSI Medience Corporation. We were unable to collect saliva samples from some participants because they did not open their mouths wide enough for saliva collection.

\section{Nutrient survey of meals}

Nutrient analysis of food intake for 3 consecutive days before and at the end of the ingestion period was performed by weighing all dishes before and after eating and calculating the ingested nutrient components on the basis of the menu. This survey was done by Kanagawa Institute of Technology.

\section{Statistical analysis}

Data are expressed as individual values or means \pm standard deviation. Statistical differences between the two groups were determined by ANCOVA using baseline values as covariates. The Wilcoxon's signed-rank test was performed to compare parameters before and at the end of the ingestion period, and Fisher's exact test was performed to compare categorical values. As a post hoc analysis, stratified analysis by median age ( 86 years) and nursing care level (groups 1 to 3 and groups 4 and 5) [11] was done. A nursing care level of 4 or more means that an elderly person is not able to perform almost all ordinary activities without help. All tests were performed at the 5\% significance level. Statistical analysis was done using the SPSS software (version 22, IBM Japan, Tokyo, Japan) by Kanagawa Institute of Technology. 


\section{RESULTS}

\section{Participant characteristics}

Eighty-eight participants (73 women and 15 men) were enrolled in the trial. The mean age was $86.3 \pm 7.8$ years, and the mean nursing care level was $3.7 \pm 1.1$. Forty-four participants were allocated to the LcS group (22 residents of MK and 22 residents of MY), and 44 participants were allocated to the placebo group (22 residents of MK and 22 residents of MY).

Sixty-eight participants (57 women and 11 men) finished the trial (Table 1). Of the 20 who did not complete the trial, 15 died before trial completion and 5 withdrew. Ingestion of the test drink was not related to cause of death as judged by the principal medical doctors. Thirty-five participants (17 residents of MK and 18 residents of MY) in the LcS group and 33 participants (16 residents of MK and 17 residents of MY) in the placebo group finished the trial. There were no significant differences between the two groups in terms of gender ratio, number in each facility, age, or nursing care level (Table 1).

\section{Data analysis of fever, bowel movements, diarrhea,} suppository use, and enema use

In the pre-ingestion and ingestion periods, no records on pyrexia were available for 5 participants, and no records of bowel movements, diarrhea, or suppository and enema use were available for 8 participants. The LcS group developed fever on an average of 0.90 days/person in the 6-month pre-ingestion period and 0.92 days/person in the 6-month ingestion period. The placebo group developed fever on an average of 1.22 days/person in the pre-ingestion period and as many as 2.89 days/person in the ingestion period (Table 2 ). The increase in the number of days on which fever was recorded was significantly greater in the placebo group than in the $\mathrm{LcS}$ group $(\mathrm{p}=0.026)$. In the $\mathrm{LcS}$ group, the mean duration of fever in the pre-ingestion period was almost the same as that in the ingestion period. In contrast, in the placebo group, the duration of fever in the ingestion period was double that in the pre-ingestion period (Table 2). The increase in the mean duration of fever was also significantly greater in the placebo group than in the $\mathrm{LcS}$ group ( $\mathrm{p}=0.022$ ). In the placebo group, the number of instances of fever in the ingestion period was significantly higher than that in the pre-ingestion period $(\mathrm{p}=0.001)$. In contrast, there was no difference in this number between the two periods in the LcS group $(\mathrm{p}=0.967)$. The increase in the number of fever instances was not significantly greater in the placebo group than in the $\operatorname{LcS}$ group $(\mathrm{p}=0.051)$.

For number of days per month on which bowel movements were recorded and for the number of bouts of diarrhea and number of uses of suppositories or enemas per 6-month period, the changes from the pre-ingestion period to the ingestion period were not significantly different between the two groups (Table 2).
Table 1. Characteristics of the participants who completed the trial

\begin{tabular}{lccc}
\hline & $\begin{array}{c}\text { LcS group } \\
(\mathrm{n}=35)\end{array}$ & $\begin{array}{c}\text { Placebo group } \\
(\mathrm{n}=33)\end{array}$ & $\mathrm{p}$ value \\
\hline Women & 28 & 29 & \multirow{2}{*}{0.514} \\
Men & 7 & 4 & \\
\hline MK residents & 17 & 16 & \multirow{2}{*}{1.000} \\
MY residents & 18 & 17 & \\
\hline Age (mean $\pm \mathrm{SD})$ & $84.9 \pm 8.5$ & $86.6 \pm 7.7$ & 0.393 \\
\hline Nursing care level $($ mean $\pm \mathrm{SD})$ & $3.8 \pm 1.1$ & $3.6 \pm 1.1$ & 0.610 \\
\hline
\end{tabular}

Fisher's exact test was performed for categorical data. An unpaired t-test was performed for numerical data.

\section{Analysis of data on peripheral blood and saliva sIgA}

Before or at the end of the ingestion period, no records of serum iron and copper levels were available for 8 participants, no records of serum zinc levels were available for 10 participants, no records of SI and serum CD4/CD8 levels were available for 4 participants, and no records of salivary sIgA were available for 10 participants. The serum iron level in the LcS group and the serum zinc levels in both groups at the end of the ingestion period were higher than those before the ingestion period, but the changes between before and at the end of the ingestion period in these parameters were not significantly different between the two groups (Table 2). SI at the end of the ingestion period in the placebo group was significantly higher than that before the ingestion period $(\mathrm{p}=0.002)$, but when the changes between the two periods were compared, there was no significant difference between the two groups. The salivary sIgA concentration did not differ significantly between the two groups when the changes between the two periods were compared.

\section{Analysis of data on organic acid concentrations and microbiota in fecal samples}

Before or at the end of the ingestion period, no records of fecal organic acid content were available for 6 participants, and no records of fecal microbiota content were available for 7 participants. Acetic acid, propionic acid, and butyric acid were major components of organic acid in the fecal samples. The concentrations of total organic acid, acetic acid, propionic acid, and butyric acid in the fecal samples did not differ significantly between the two groups (Table 3 ). The number of Bifidobacterium cells at the end of the ingestion period in the LcS group was significantly higher than that before the ingestion period, and the numbers of Enterobacteriaceae at the end of ingestion period in both groups were significantly lower than those before the ingestion period, but when the changes between two periods were compared, there were no significant differences between the two groups (Table 3).

\section{Analysis of data for weight, body mass index, and nutrient content of meals}

We performed a data analysis on the data collected for weight, body mass index (BMI), and nutrient content of meals 
Table 2. Data for fever, bowel habits, peripheral blood parameters, and saliva sIgA

\begin{tabular}{|c|c|c|c|c|c|c|}
\hline Item & Group & $\mathrm{N}$ & $\begin{array}{l}\text { Pre-ingestion period } \\
\quad(\text { mean } \pm \text { SD })\end{array}$ & $\begin{array}{l}\text { Ingestion period } \\
(\text { mean } \pm \mathrm{SD})\end{array}$ & $\mathrm{p}$ value $*$ & p value ${ }^{\#}$ \\
\hline \multirow[t]{2}{*}{ Days of fever (days/6 months) } & $\mathrm{LcS}$ & 32 & $0.90 \pm 1.50$ & $0.92 \pm 1.88$ & 0.966 & 0.026 \\
\hline & Placebo & 31 & $1.22 \pm 2.72$ & $2.89 \pm 4.87$ & 0.001 & \\
\hline \multirow[t]{2}{*}{ Duration of fever days (days) } & LcS & 32 & $0.45 \pm 0.73$ & $0.45 \pm 0.78$ & 0.984 & 0.022 \\
\hline & Placebo & 31 & $0.52 \pm 0.81$ & $1.17 \pm 1.57$ & 0.090 & \\
\hline \multirow[t]{2}{*}{ Fever incidences (incidences/6 months) } & $\mathrm{LcS}$ & 32 & $0.62 \pm 0.97$ & $0.64 \pm 1.28$ & 0.967 & 0.051 \\
\hline & Placebo & 31 & $0.85 \pm 1.81$ & $1.65 \pm 2.81$ & 0.001 & \\
\hline \multirow[t]{2}{*}{ Number of bowel movements (times/month) } & $\mathrm{LcS}$ & 31 & $29.83 \pm 18.10$ & $30.86 \pm 19.49$ & 0.804 & 0.507 \\
\hline & Placebo & 29 & $28.87 \pm 14.69$ & $28.57 \pm 12.47$ & 0.875 & \\
\hline \multirow[t]{2}{*}{ Days of bowel movements (days/month) } & $\mathrm{LcS}$ & 31 & $18.50 \pm 6.41$ & $18.60 \pm 6.61$ & 0.789 & 0.574 \\
\hline & Placebo & 29 & $18.85 \pm 6.26$ & $18.46 \pm 5.64$ & 0.356 & \\
\hline \multirow[t]{2}{*}{ Number of diarrhea episodes (times/6 months) } & LcS & 31 & $24.38 \pm 58.85$ & $19.64 \pm 33.83$ & 0.673 & 0.197 \\
\hline & Placebo & 29 & $27.44 \pm 30.49$ & $29.88 \pm 34.78$ & 0.561 & \\
\hline \multirow[t]{2}{*}{ Number of suppositories (times/6 months) } & LcS & 31 & $1.28 \pm 2.75$ & $1.01 \pm 2.45$ & 0.878 & 0.787 \\
\hline & Placebo & 29 & $0.97 \pm 2.89$ & $0.94 \pm 2.65$ & 0.731 & \\
\hline \multirow[t]{2}{*}{ Number of enemas (times/6 months) } & LcS & 31 & $1.48 \pm 7.69$ & $1.65 \pm 8.08$ & 0.078 & 0.808 \\
\hline & Placebo & 29 & $0.07 \pm 0.26$ & $0.14 \pm 0.44$ & 0.250 & \\
\hline \multirow[t]{2}{*}{ Albumin (g/dL) } & $\mathrm{LcS}$ & 31 & $3.52 \pm 0.44$ & $3.58 \pm 0.49$ & 0.192 & 0.124 \\
\hline & Placebo & 29 & $3.64 \pm 0.43$ & $3.56 \pm 0.52$ & 0.257 & \\
\hline \multirow[t]{2}{*}{ Iron $(\mu \mathrm{g} / \mathrm{dL})$} & $\mathrm{LcS}$ & 31 & $69.1 \pm 19.9$ & $75.6 \pm 26.2$ & 0.018 & 0.415 \\
\hline & Placebo & 29 & $68.7 \pm 25.7$ & $71.3 \pm 28.6$ & 0.723 & \\
\hline \multirow[t]{2}{*}{ Copper $(\mu \mathrm{g} / \mathrm{dL})$} & $\mathrm{LcS}$ & 31 & $95.4 \pm 27.1$ & $100.0 \pm 29.4$ & 0.054 & 0.850 \\
\hline & Placebo & 29 & $106.7 \pm 19.5$ & $109.5 \pm 19.5$ & 0.117 & \\
\hline \multirow[t]{2}{*}{ Zinc $(\mu \mathrm{g} / \mathrm{dL})$} & LcS & 31 & $64.1 \pm 10.8$ & $76.5 \pm 11.0$ & $<0.001$ & 0.543 \\
\hline & Placebo & 27 & $67.3 \pm 9.6$ & $77.5 \pm 10.4$ & $<0.001$ & \\
\hline \multirow[t]{2}{*}{ Stimulation index } & LcS & 34 & $192.82 \pm 81.79$ & $210.56 \pm 87.55$ & 0.657 & 0.102 \\
\hline & Placebo & 30 & $161.61 \pm 84.18$ & $250.04 \pm 113.76$ & 0.002 & \\
\hline \multirow[t]{2}{*}{$\mathrm{CD} 4 / \mathrm{CD} 8$} & $\mathrm{LcS}$ & 33 & $1.652 \pm 0.937$ & $1.786 \pm 1.109$ & 0.707 & 0.818 \\
\hline & Placebo & 30 & $1.324 \pm 0.741$ & $1.541 \pm 0.976$ & 0.082 & \\
\hline \multirow[t]{2}{*}{ Saliva sIgA $(\mu \mathrm{g} / \mathrm{mL})$} & $\mathrm{LcS}$ & 30 & $494.2 \pm 515.3$ & $455.6 \pm 537.4$ & 0.507 & 0.423 \\
\hline & Placebo & 28 & $400.3 \pm 324.1$ & $526.4 \pm 382.0$ & 0.071 & \\
\hline
\end{tabular}

*Wilcoxon signed-rank test was performed. \#ANCOVA was performd. LcS: Lactobacillus casei strain Shirota.

Table 3. Data for fecal organic acid concentrations and microbiota

\begin{tabular}{|c|c|c|c|c|c|c|}
\hline Item & Group & $\mathrm{N}$ & $\begin{array}{l}\text { Pre-ingestion period } \\
\quad(\text { mean } \pm \text { SD })\end{array}$ & $\begin{array}{l}\text { Ingestion period } \\
(\text { mean } \pm \text { SD })\end{array}$ & $\mathrm{p}$ value * & $\mathrm{p}$ value ${ }^{\#}$ \\
\hline \multirow[t]{2}{*}{ Acetic acid (mM) } & $\mathrm{LcS}$ & 31 & $68.80 \pm 29.45$ & $61.85 \pm 35.84$ & 0.425 & 0.604 \\
\hline & Placebo & 31 & $65.78 \pm 24.34$ & $63.28 \pm 25.78$ & 0.431 & \\
\hline \multirow[t]{2}{*}{ Propionic acid (mM) } & $\mathrm{LcS}$ & 31 & $16.89 \pm 9.91$ & $14.59 \pm 10.58$ & 0.133 & 0.687 \\
\hline & Placebo & 31 & $18.48 \pm 10.31$ & $16.37 \pm 9.50$ & 0.350 & \\
\hline \multirow[t]{2}{*}{ Butyric acid (mM) } & $\mathrm{LcS}$ & 31 & $9.68 \pm 7.28$ & $8.33 \pm 9.51$ & 0.231 & 0.794 \\
\hline & Placebo & 31 & $14.23 \pm 10.88$ & $12.28 \pm 10.64$ & 0.174 & \\
\hline \multirow[t]{2}{*}{ Total organic acids (mM) } & $\mathrm{LcS}$ & 31 & $102.93 \pm 48.13$ & $91.64 \pm 55.51$ & 0.223 & 0.511 \\
\hline & Placebo & 31 & $107.05 \pm 48.03$ & $101.40 \pm 50.03$ & 0.326 & \\
\hline \multirow[t]{2}{*}{ Bifidobacterium $\left(\log _{10}\right.$ cells/g feces) } & $\mathrm{LcS}$ & 30 & $8.42 \pm 1.20$ & $8.76 \pm 1.07$ & 0.027 & 0.712 \\
\hline & Placebo & 31 & $8.64 \pm 1.01$ & $8.81 \pm 1.18$ & 0.203 & \\
\hline \multirow[t]{2}{*}{ C. perfringens $\left(\log _{10}\right.$ cells/g feces) } & $\mathrm{LcS}$ & 30 & $6.24 \pm 2.13$ & $6.15 \pm 2.26$ & 0.761 & 0.876 \\
\hline & Placebo & 31 & $5.70 \pm 2.64$ & $5.65 \pm 2.77$ & 0.275 & \\
\hline \multirow[t]{2}{*}{ Enterobacteriaceae $\left(\log _{10}\right.$ cells/g feces) } & $\mathrm{LcS}$ & 30 & $7.73 \pm 1.32$ & $6.78 \pm 2.01$ & 0.004 & 0.623 \\
\hline & Placebo & 31 & $7.08 \pm 1.34$ & $6.44 \pm 1.87$ & 0.013 & \\
\hline
\end{tabular}

*Wilcoxon signed-rank test was performed. ${ }^{*}$ ANCOVA was performd. LcS: Lactobacillus casei strain Shirota. 
(Table 4). Calcium intake at the end of the ingestion period was significantly lower than before the ingestion period in both groups. Weight, BMI, and nutrient intake did not differ significantly between the two groups when the changes between two periods were compared.

\section{Post hoc stratified analysis}

Because the number of days on which fever was detected differed significantly between the two groups, we stratified the subjects by median age and nursing care level to elucidate a group in which the fermented milk drink was more efficient (Table 5). The change in the number of days on which fever was detected between the pre-ingestion period and the ingestion period was significantly higher in members of the placebo group aged $\geq 86$ years than in members of the LcS group in the same age bracket $(\mathrm{p}=0.008)$. In contrast, there was no significant difference in the subgroup of members aged $<86$ years $(p=0.678)$. In subjects whose nursing care level was 4 or 5 , the increase in the number of days on which fever was detected between the two periods was significantly higher in the placebo group than in the LcS group $(\mathrm{p}=0.016)$, but in subjects whose nursing care level was 1 to 3 , no significant difference was observed $(p=0.535)$.

\section{DISCUSSION}

Our findings showed that continuous intake of the fermented milk drink reduced the number of days on which fever was detected and the duration of fever, both of which usually increase in winter. These results were consistent with those of previous studies [4-7]. In the LcS group, the number of days on which fever was detected and the duration of fever during the ingestion period were almost the same as those in the pre-ingestion period. On the other hand, in the ingestion period in the placebo group, the values of these parameters were more than double those in the pre-ingestion period. In the elderly, it is beneficial to shorten the duration of fever because persistent fever can lead to dehydration and more severe complications [2, 3]. Frequent pyrexia or long-term duration of pyrexia would worsen the quality of life of elderly subjects and lead to deterioration of the exercise ability. This study showed that ingestion of the fermented milk drink, especially in winter, would maintain the health condition of elderly subjects. The study design was based on a previous trial [7]. The previous study was a randomized, double-blind, placebo-controlled parallel study performed to investigate the effects of a fermented milk drink containing LcS. The ingestion period of the previous study was 6 months, and the number of randomized elderly subjects was $88 ; 72$ subjects finished the trial. The results of the study revealed that the $\mathrm{LcS}$ group showed lower incidence of fever and improved bowel movements compared with the placebo group [7]. The ingestion period of this study was set to 6 months, and 88 subjects were randomized to the study groups. Sixty-eight subjects of the 88 subjects completed the trial. The number of withdrawn subjects in this study was comparable to that of the previous study. In Table 2, the baseline data for days of fever and duration of fever days in the placebo group was higher than those in the LcS group. We applied ANCOVA analysis using baseline values as covariates to evaluate the effects of the fermented milk drink; therefore, the higher baseline value in the placebo group compared with the LcS group would not affect the results.

By analyzing the peripheral blood, saliva $\operatorname{sIgA}$, and microbiota, we expected that we would be able to elucidate the mechanism by which the fermented milk drink helped to prevent infectious disease. However, mineral levels, immune parameters such as SI and saliva $\operatorname{sIgA}$, and microbiota of the $\mathrm{LcS}$ group in the ingestion period were not significantly improved compared with those of the placebo group. Takeda et al. showed that NK cell activity increased significantly after ingestion of a fermented milk drink containing $\mathrm{LcS}$ for 3 weeks [8]. The study design was cross-over trial using a fermented milk drink and a placebo drink with 10 elderly subjects (aged 69-97 years). On the other hand, we could not detect significant immune modulation activity of $\mathrm{LcS}$ in this study. The ingestion period of this study was 6 months and we collected blood samples before and at the end of the ingestion period but could not collect them periodically (e.g., monthly or every 3 months) because frequent blood sampling is a burden on the elderly. We might have missed the times when the immune modulation was activated by LcS. In addition, the nursing care levels of the subjects in this study were high, and it might be difficult to detect significant differences in immune modulation activity in these subjects. These differences might contribute to failing to detect immune modulation activity in this trial. Based on our examination of several parameters, we could not clarify the mechanism by which LcS had a health benefit in the elderly. In the case of a trial with elderly subjects, surrogate markers that can be obtained noninvasively and periodically are prerequisite to elucidate the mechanism of the effects of the fermented milk drink.

Our stratified analysis revealed that, in the placebo group, subjects aged $\geq 86$ years or at nursing care level 4 or 5 developed fever more frequently in the ingestion period than in the pre-ingestion period ( $\mathrm{p}=0.002$ and 0.020 , respectively, Table 5). These results showed that older persons and those who needed more care were more vulnerable to winter infections. In contrast, in both of these subgroups in the $\mathrm{LcS}$ group, the number of days on which fever was detected tended to be lower during the ingestion period than in the pre-ingestion period. The number of subjects aged $\geq 86$ years in the placebo group was 19, and that in the LcS group was 15. We considered that this difference would not affect the results because the difference between the ingestion period and the pre-ingestion period of each subject was evaluated by ANCOVA using the baseline values as covariates.

The mean daily energy intake in the two groups was around $1,000 \mathrm{kcal}$, which is less than the recommendation of the Japanese Ministry of Health, Labor and Welfare [14]. However, mean body weight was constant during the study period (Table 4). Therefore, energy intake and energy 
Table 4. Data for weight, body mass index, and nutrient content of meals

\begin{tabular}{|c|c|c|c|c|c|c|}
\hline Item & Group & $\mathrm{N}$ & $\begin{array}{l}\text { Pre-ingestion period } \\
\quad(\text { mean } \pm \text { SD })\end{array}$ & $\begin{array}{l}\text { Ingestion period } \\
(\text { mean } \pm \text { SD })\end{array}$ & p value* & $\mathrm{p}$ value $^{\#}$ \\
\hline \multirow[t]{2}{*}{ Weight (kg) } & $\mathrm{LcS}$ & 35 & $43.77 \pm 10.07$ & $42.73 \pm 10.88$ & 0.194 & 0.311 \\
\hline & Placebo & 33 & $44.73 \pm 8.22$ & $44.59 \pm 8.08$ & 0.937 & \\
\hline \multirow[t]{2}{*}{ BMI $\left(\mathrm{kg} / \mathrm{m}^{2}\right)$} & $\mathrm{LcS}$ & 35 & $20.43 \pm 3.43$ & $19.93 \pm 3.74$ & 0.183 & 0.187 \\
\hline & Placebo & 33 & $21.05 \pm 3.21$ & $21.10 \pm 3.18$ & 0.773 & \\
\hline \multirow[t]{2}{*}{ Energy (kcal) } & $\mathrm{LcS}$ & 35 & $1,060.8 \pm 256.7$ & $1,026.3 \pm 246.5$ & 0.309 & 0.800 \\
\hline & Placebo & 33 & $1,053.0 \pm 267.9$ & $1,034.7 \pm 273.7$ & 0.979 & \\
\hline \multirow[t]{2}{*}{ Protein (g) } & $\mathrm{LcS}$ & 35 & $38.84 \pm 9.05$ & $36.97 \pm 9.72$ & 0.106 & 0.940 \\
\hline & Placebo & 33 & $37.90 \pm 13.94$ & $36.36 \pm 9.44$ & 0.787 & \\
\hline \multirow[t]{2}{*}{ Fat (g) } & $\mathrm{LcS}$ & 35 & $26.63 \pm 6.93$ & $25.12 \pm 7.42$ & 0.082 & 0.368 \\
\hline & Placebo & 33 & $25.80 \pm 8.54$ & $25.90 \pm 6.52$ & 0.668 & \\
\hline \multirow[t]{2}{*}{ Carbohydrate (g) } & $\mathrm{LcS}$ & 35 & $160.60 \pm 47.61$ & $157.27 \pm 44.30$ & 0.574 & 0.965 \\
\hline & Placebo & 33 & $162.11 \pm 46.87$ & $158.49 \pm 46.65$ & 0.958 & \\
\hline \multirow[t]{2}{*}{ Sodium (mg) } & $\mathrm{LcS}$ & 35 & $2,284.4 \pm 775.3$ & $2,209.5 \pm 783.6$ & 0.286 & 0.950 \\
\hline & Placebo & 33 & $2,155.5 \pm 883.0$ & $2,125.4 \pm 744.1$ & 0.760 & \\
\hline \multirow[t]{2}{*}{ Potassium (mg) } & $\mathrm{LcS}$ & 35 & $1,383.8 \pm 385.0$ & $1,288.8 \pm 384.6$ & 0.172 & 0.078 \\
\hline & Placebo & 33 & $1,249.7 \pm 418.1$ & $1,332.4 \pm 455.8$ & 0.175 & \\
\hline \multirow[t]{2}{*}{ Calcium (mg) } & $\mathrm{LcS}$ & 35 & $396.2 \pm 132.7$ & $329.7 \pm 131.6$ & $<0.001$ & 0.853 \\
\hline & Placebo & 33 & $395.7 \pm 115.3$ & $323.8 \pm 142.8$ & 0.023 & \\
\hline \multirow[t]{2}{*}{ Magnesium (mg) } & $\mathrm{LcS}$ & 35 & $166.1 \pm 49.1$ & $155.5 \pm 48.4$ & 0.085 & 0.921 \\
\hline & Placebo & 33 & $145.0 \pm 57.0$ & $145.0 \pm 47.1$ & 0.747 & \\
\hline \multirow[t]{2}{*}{ Soluble fiber (g) } & $\mathrm{LcS}$ & 35 & $2.92 \pm 1.14$ & $2.91 \pm 1.09$ & 0.885 & 0.538 \\
\hline & Placebo & 33 & $2.81 \pm 1.34$ & $3.01 \pm 1.29$ & 0.189 & \\
\hline \multirow[t]{2}{*}{ Insoluble fiber (g) } & $\mathrm{LcS}$ & 35 & $6.22 \pm 2.15$ & $6.28 \pm 2.25$ & 0.677 & 0.821 \\
\hline & Placebo & 33 & $5.89 \pm 2.27$ & $5.96 \pm 2.33$ & 0.728 & \\
\hline \multirow[t]{2}{*}{ Total fiber (g) } & $\mathrm{LcS}$ & 35 & $9.57 \pm 3.03$ & $9.51 \pm 2.96$ & 0.791 & 0.863 \\
\hline & Placebo & 33 & $9.65 \pm 3.38$ & $9.65 \pm 2.81$ & 0.924 & \\
\hline \multirow[t]{2}{*}{ Sodium chloride equivalent (g) } & $\mathrm{LcS}$ & 35 & $5.79 \pm 1.96$ & $5.62 \pm 2.01$ & 0.333 & 0.828 \\
\hline & Placebo & 33 & $5.46 \pm 2.27$ & $5.44 \pm 1.91$ & 0.937 & \\
\hline
\end{tabular}

*Wilcoxon signed-rank test was performed. ${ }^{*}$ ANCOVA was performd. BMI: body mass index; LcS: Lactobacillus casei strain Shirota.

Table 5. Stratified analysis of the number of days on which fever was detected by age and nursing care level

\begin{tabular}{|c|c|c|c|c|c|c|c|}
\hline Item & Stratified value & Group & $\mathrm{N}$ & $\begin{array}{l}\text { Pre-ingestion period } \\
\text { (days / } 6 \text { months) }\end{array}$ & $\begin{array}{l}\text { Ingestion period } \\
\text { (days / } 6 \text { months) }\end{array}$ & p value* & $\mathrm{p}$ value ${ }^{\#}$ \\
\hline \multirow[t]{4}{*}{ Age } & \multirow[t]{2}{*}{$<86$} & $\mathrm{LcS}$ & 17 & $0.94 \pm 1.55$ & $1.43 \pm 2.31$ & 0.432 & \multirow[t]{2}{*}{0.678} \\
\hline & & Placebo & 12 & $1.08 \pm 1.50$ & $1.84 \pm 2.60$ & 0.473 & \\
\hline & \multirow[t]{2}{*}{$\geq 86$} & $\mathrm{LcS}$ & 15 & $0.86 \pm 1.50$ & $0.33 \pm 1.05$ & 0.625 & \multirow[t]{2}{*}{0.008} \\
\hline & & Placebo & 19 & $1.31 \pm 3.31$ & $3.55 \pm 5.85$ & 0.002 & \\
\hline \multirow[t]{4}{*}{ Nursing care level } & \multirow[t]{2}{*}{1 to 3} & $\mathrm{LcS}$ & 10 & $1.00 \pm 1.48$ & $1.83 \pm 2.83$ & 0.563 & \multirow[t]{2}{*}{0.535} \\
\hline & & Placebo & 12 & $2.08 \pm 3.98$ & $4.35 \pm 7.16$ & 0.078 & \\
\hline & \multirow[t]{2}{*}{4 and 5} & $\mathrm{LcS}$ & 22 & $0.86 \pm 1.55$ & $0.50 \pm 1.11$ & 0.633 & \multirow[t]{2}{*}{0.016} \\
\hline & & Placebo & 19 & $0.68 \pm 1.37$ & $1.97 \pm 2.44$ & 0.020 & \\
\hline
\end{tabular}

*Wilcoxon signed-rank test was performed. \#ANCOVA was performd. LcS: Lactobacillus casei strain Shirota.

consumption were well balanced, and participants were considered to have sufficient energy for their activities. The estimated mean necessary protein intake for elderly people, based on a pooled analysis of five studies, is $0.85 \mathrm{~g} / \mathrm{kg}$ weight/ day, as proposed by Japanese Ministry of Health, Labor and
Welfare [14]. The mean body weight of the participants was around $44 \mathrm{~kg}$; therefore, a protein intake of $37 \mathrm{~g}$ would have been well balanced. Mean total fiber intake in the two groups during the study was less than $10 \mathrm{~g}$, which is about half the recommendation of the Japanese Ministry of Health, Labor 
and Welfare [14]. As shown in Table 2, bowel movements, enema administration, and diarrhea frequency during the ingestion period in the LcS group were not improved compared with those in the pre-ingestion period. Suboptimal fiber intake was likely one of the reasons for the lack of improvement in bowel habits. Not only drinking the fermented milk drink but also consuming sufficient fiber may be necessary to improve bowel habits. We calculated the frequency of diarrhea but did not record the severity of diarrhea. The severity of diarrhea is one of the important parameters to evaluate the effect of the fermented milk drink. We are planning to record the severity of diarrhea in the next trial.

After ingestion of the fermented milk drink, the number of Bifidobacterium cells increased, and the number of Enterobacteriaceae decreased (Table 3). These results were consistent with those of previous reports $[4,5,7]$. In a report by Nagata et al., the number of Bifidobacterium cells did not increase and the number of Enterobacteriaceae did not decrease, rather increased, during the ingestion period in the placebo group, leading to a significant difference between the LcS group and the placebo group [7]. In this study, although the number of Bifidobacterium cells increased and the number of Enterobacteriaecea decreased as a result of ingesting the fermented milk, we could not detect any significant differences between the two groups because similar trends were detected in the placebo group. Bifidobacterium cells were detected at the level of $10^{8}$ per $g$ feces in the two groups throughout the trial period. These values were at the same level as in previous reports [4, 5, 7]. In the case of Enterobacteriaceae, the numbers of cells in the pre-ingestion period were at the level of $10^{7}$ in both groups, and these values were about 10 times lower than in previous reports $[4,5,7]$. We could not explain why fewer Enterobacteriaceae cells were detected in the subjects of this study. We did not measure the cfu of $\mathrm{LcS}$ in feces in this study. It would have been necessary to collect feces into another sampling tube, store them in a refrigerator, and transport them within several days in order to measure live LcS in feces. These procedures would have overloaded the nursing staff; therefore, we decided not to measure LcS in this study. In previous studies, LcS were detected at the level of $10^{8} \mathrm{cfu} / \mathrm{g}$ feces $[4,5]$.

In conclusion, continuous intake of a fermented milk drink by the elderly may reduce the number of days on which fever is detected and the duration of fever. Further studies are required to clarify the mechanism by which the fermented milk drink exerts these prophylactic effects.

\section{CONFLICT OF INTEREST AND FUNDING DISCLOSURE}

A. Kushiro, K. Shimizu, and T. Takada are staff members of Yakult Central Institute. The other authors declare that they are free of any conflicts of interest. This study was funded by Yakult Honsha Co., Ltd.

\section{ACKNOWLEDGMENT}

We thank Soichi Ueno (Director of Morinoie Yashio facility), Koji Ueno (Director of Morinoie Katori facility), and all of their staff.

\section{REFERENCES}

1. Gerba CP, Rose JB, Haas CN. 1996. Sensitive populations: who is at the greatest risk? Int J Food Microbiol 30: 113-123. [Medline] [CrossRef]

2. Weinberg AD, Pals JK, Levesque PG, Beal LF, Cunningham TJ, Minaker KL. 1994. Dehydration and death during febrile episodes in the nursing home. J Am Geriatr Soc 42: 968-971. [Medline] [CrossRef]

3. Pals JK, Weinberg AD, Beal LF, Levesque PG, Cunningham TJ, Minaker KL. 1995. Clinical triggers for detection of fever and dehydration. Implications for long-term care nursing. J Gerontol Nurs 21: 13-19. [Medline] [CrossRef]

4. Bian L, Nagata S, Asahara T, Rahman MS, Ohta T, Yuki N, Wang C, Takano K, Daibo M, Nomoto K, Yamashiro Y. 2011. Effects of the continuous intake of Lactobacillus casei strain Shirota-fermented milk on risk management of longterm inpatients at health service facilities for the elderly. Int J Probiotics Prebiotics 6: $123-132$.

5. Nagata S, Asahara T, Ohta T, Yamada T, Kondo S, Bian L, Wang C, Yamashiro Y, Nomoto K. 2011. Effect of the continuous intake of probiotic-fermented milk containing Lactobacillus casei strain Shirota on fever in a mass outbreak of norovirus gastroenteritis and the faecal microflora in a health service facility for the aged. Br J Nutr 106: 549-556. [Medline] [CrossRef]

6. Fujita R, Iimuro S, Shinozaki T, Sakamaki K, Uemura Y, Takeuchi A, Matsuyama Y, Ohashi Y. 2013. Decreased duration of acute upper respiratory tract infections with daily intake of fermented milk: a multicenter, double-blinded, randomized comparative study in users of day care facilities for the elderly population. Am J Infect Control 41: 1231-1235. [Medline] [CrossRef]

7. Nagata S, Asahara T, Wang C, Suyama Y, Chonan O, Takano K, Daibou M, Takahashi T, Nomoto K, Yamashiro Y. 2016. The effectiveness of Lactobacillus beverages in controlling infections among the residents of an aged care facility: a randomized placebo-controlled double-blind trial. Ann Nutr Metab 68: 51-59. [Medline] [CrossRef]

8. Takeda K, Suzuki T, Shimada SI, Shida K, Nanno M, Okumura K. 2006 Interleukin-12 is involved in the enhancement of human natural killer cell activity by Lactobacillus casei Shirota. Clin Exp Immunol 146: 109-115. [Medline] [CrossRef]

9. Dong H, Rowland I, Thomas LV, Yaqoob P. 2013. Immunomodulatory effects of a probiotic drink containing Lactobacillus casei Shirota in healthy older volunteers Eur J Nutr 52: 1853-1863. [Medline] [CrossRef]

10. Sekita Y, Tokita K, Nishiyama Y, Namatame K, Uchida K, Kushiro A, Aiba N. 2015. Case report of bowel habit improvement in elderly in a nursing home by continuous intake of fermented milk products. J Jpn Diet Assoc 58: 440-445 (Abstract in English, article in Japanese).

11. Japanese Ministry of Health, Labor, and Welfare. 2009. Text of primary nursing care requirement authorization. Available at: http://www.mhlw.go.jp/topics/kaigo/ nintei/d1/text2009 2.pdf (in Japanese)

12. Matsuda K, Tsuji H, Asahara T, Matsumoto K, Takada T, Nomoto K. 2009. Establishment of an analytical system for the human fecal microbiota, based on reverse transcription-quantitative PCR targeting of multicopy rRNA molecules. Appl Environ Microbiol 75: 1961-1969. [Medline] [CrossRef]

13. Matsumoto K, Takada T, Shimizu K, Moriyama K, Kawakami K, Hirano K, Kajimoto O, Nomoto K. 2010. Effects of a probiotic fermented milk beverage containing Lactobacillus casei strain Shirota on defecation frequency, intestinal microbiota, and the intestinal environment of healthy individuals with soft stools. J Biosci Bioeng 110: 547-552. [Medline] [CrossRef]

14. Japanese Ministry of Health, Labor, and Welfare. 2018. Dietary reference intakes for Japanese. Available at: http://www.mhlw.go.jp/file/06-Seisakujouhou10900000-Kenkoukyoku/Full_DRIs2015.pdf 